\title{
Documento
}

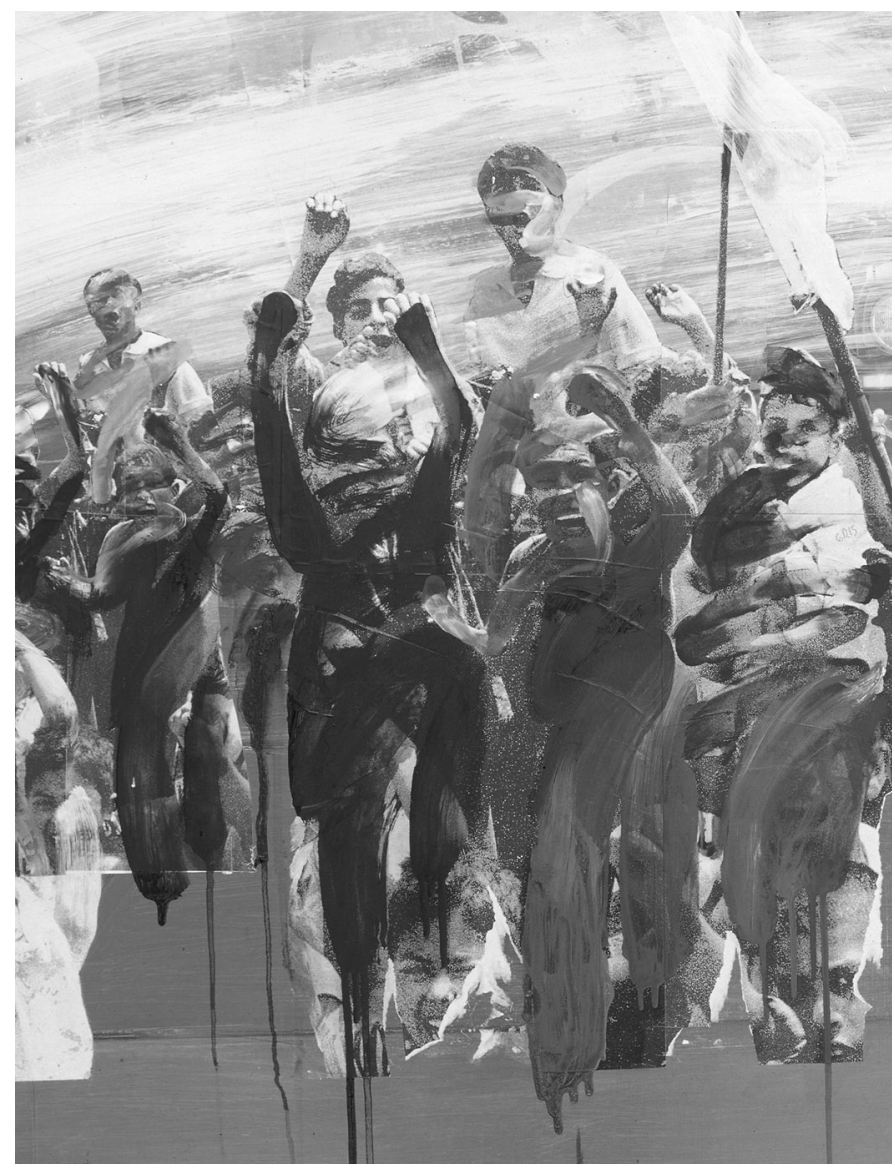




\section{Discurso proferido por Francisco Clementino San Tiago Dantas em agradecimento pelo prêmio "Homem de Visão de 1963", outorgado pela Revista Visão}

Dono de uma biografia cujas ações se confundem com os momentos cruciais do Brasil nos meados do século XX, San Tiago Dantas freqüentou o alto escalão integralista nos anos 30. Com o Estado Novo dedicou-se, com grande sucesso, à vida acadêmica, tendo ocupado diversas cadeiras de ciências jurídicas e econômicas na Universidade do Brasil (RJ). Assessor pessoal de Getúlio Vargas, nos anos 50 atuou na implementação da Petrobrás e na reorganização da estrutura ferroviária nacional com a criação da Rede Ferroviária Federal, entre outras tarefas governamentais de magno valor. Foi proprietário e editor do Jornal do Comércio do Rio de Janeiro, no qual defendeu com denodo o projeto nacionalista do seu PTB. Como ministro das relações exteriores (de setembro de 1961 a julho de 1962) liderou ação pela integração de Cuba revolucionária à política continental, em oposição aos EUA. Com a volta do presidencialismo (1963), San Tiago Dantas assumiu o Ministério da Fazenda para travar uma batalha pela racionalização da ação do governo por meio da execução das reformas administrativa e bancária, duas das então denominadas "Reformas de Base", do governo João Goulart.

O documento a seguir transcrito reflete um momento de tensão tanto da vida nacional, já que o país vivia o pré-golpe de março de 1964, como das lutas políticas de San Tiago Dantas. Vítima de um câncer que iria matá-lo pouco depois (6 de setembro de 1964), o homenageado aproveitou a oportunidade para prestar contas a seus críticos. Identifica-se com a ampliação do processo democrático, com a extensão "ao povo de benefícios até então de poucos" e a conseqüente "redistribuição da renda social", com o fim de inserir o país em um tempo de justiça e progresso. Da produtiva leitura do seu discurso, depreende-se um dos cânones da luta pela democracia social na época: San Tiago Dantas dedicava todo o seu ânimo para tentar compatibilizar os interesses do capital, nacional e estrangeiro, com os projetos nacionais populares. O golpe político-militar congelou todas essas aspirações. 
Desejo, em primeiro lugar, agradecer à Revista Visão, na pessoa de seu brilhante diretor Jorge Leão Teixeira, e ao seu ilustre corpo de jurados, a generosidade com que resolveram outorgar-me o título de "Homem de Visão de 1963 ". Na sua própria enunciação, o título contém uma propositada ambigüidade. Uma ambigüidade, entretanto, isenta de malícia, porque ambos os sentidos que ele comporta são honrosos e, no meu caso, excedem os direitos que tenho de recebê-lo.

Se tomarmos "visão" como atributo do escolhido, quem poderá pretender ter sido o homem que "viu" — ou mesmo um dos que algo lograram divisar - na bruma ainda persistente deste 1963? E se tomarmos "Visão" como o nome consagrado da revista que há anos repete ousadamente esta escolha, que grande responsabilidade a deferir-lhe, principalmente quando ela hoje faz recair a sua preferência, não num homem cujas atitudes e opiniões têm contado com o aplauso de todos, ou de quase todos, mas que tem atraído, pelo contrário, polêmicas, discussões, e mesmo tempestades!

De outubro de 1961 a outubro de 1963, o homem agora escolhido recebeu aplausos e críticas dos mesmos grupos e setores de opinião, por atitudes que assumiu, atos políticos e administrativos que praticou, idéias que expendeu e palavras que proferiu, a ponto de se poder querer ver, na variedade dessas posições, ou incoerência ou versatilidade.

Creio que não me fica mal aproveitar a expressividade da reunião de hoje, em que observo e agradeço a presença de tantos homens representativos do país, para fazer de público o que até hoje nunca fiz: um ensaio de justificativa.

Creio que essa justificativa pode dar ensejo a que saiamos um pouco do culto à personalidade, para irmos ao encontro dos problemas, e sobretudo das opções, que se abrem ao nosso povo nesta época.

Se me fosse dado partir de duas afirmativas, ou posições, para nelas procurar envolver toda a minha conduta de homem público, procuraria reduzilas a este traçado essencial:

a) a certeza de que a sobrevivência da democracia e da liberdade, no mundo moderno, depende de nossa capacidade de estendermos a todo o povo, e não de forma potencial, mas efetiva, os benefícios, hoje reservados a uma classe dominante, dessa liberdade e da própria civilização; 
b) a certeza de que a continuidade da civilização, com o seu resultado final que é a reconciliação dos homens, depende da nossa capacidade de preservar a paz, substituindo a competição militar entre os povos por técnicas cada vez mais estáveis de cooperação e de convivência, e caminhando para uma integração econômica que nivele as oportunidades, com a rápida eliminação dos resíduos do imperialismo e das rivalidades nacionais.

A primeira dessas assertivas traz consigo a correlação inevitável entre a democracia e a reforma social. Não é exato, como aliás já são poucos os que pretendem, que a democracia possa salvar-se como fórmula política, apenas mediante o apego a certos ideais jurídicos, que deram expressão adequada, em outras épocas, a formas então válidas de supremacia social. Também não é certo, como muitos ainda querem crer, que o futuro da democracia dependa apenas do desenvolvimento econômico, e que o seu fortalecimento possa medir-se no crescimento da renda nacional ou do seu índice per capita. O crescimento da renda nacional, mesmo quando se processa a uma taxa superior à do aumento demográfico, pode reverter, graças à má distribuição social da riqueza, em benefício de setores limitados da população, e agravar temporariamente, em vez de atenuar, as tensões sociais internas, que comprometem a estabilidade das instituições democráticas e dela fazem um poderoso instrumento, não a serviço da reconciliação, mas a serviço da opressão.

Se nem a fidelidade aos princípios jurídicos, nem o crescimento da riqueza bastam para preservar a democracia e adaptá-la ao mundo moderno, é indispensável reconhecermos a necessidade de aditar a esses dois fatores um terceiro: a reforma social. E é sobre as características, o alcance e os meios de processamento dessa reforma, que o pensamento democrático, no Brasil e fora dele, não raro se torna evasivo. Dir-se-ia que para alguns a reforma social deve ficar propositadamente informulada, servindo mais de incentivo a reivindicações isoladas, que somam forças no sentido da violência, enquanto para outros é uma forma de contemporização consciente, destinada a servir de anteparo a um esforço de preservação das estruturas atuais.

Essas formas de deslealdade com a história não conseguem ser, porém, de duração prolongada. Se o pensamento democrático não for capaz de formular, em termos válidos e inteligíveis, o seu esquema de reforma social, esta abrirá seu caminho anti-democraticamente, porque, no quadro das tensões internas da sociedade atual, as forças que aspiram a uma participação mais ampla nos benefícios da vida comum são superiores em intensidade às que 
procuram deixar em segundo plano essa ampliação, para se limitarem à defesa das chamadas garantias democráticas.

Toda contemporização ou insinceridade na abertura de um rumo eficaz de reforma social se liquida, desse modo, num reforço do processo anti-democrático e na debilitação a curto prazo da própria democracia.

Sou dos que entendem que a preservação e o fortalecimento da democracia representativa constituem um objetivo inalienável da nossa civilização, e que só através dela alcançaremos uma forma de convivência política verdadeiramente isenta de opressão. Em primeiro lugar, a democracia, no quadro comparativo das instituições políticas conhecidas, não foi superada como forma de proteção do homem na sua confrontação cotidiana com o poder. Em segundo lugar, nenhum outro regime, por mais convincentes que sejam seus resultados no campo econômico ou tecnológico, logrou oferecer mecanismo mais impessoal, e mais capaz de absorver e compensar as formas primárias de violência, do que o democrático, sobretudo no episódio culminante, que é o da transferência do poder.

Para defender, aprimorar esse mecanismo e dar-lhe, em face da realidade social de hoje, maior efetividade e legitimidade, é indispensável renová-lo através da reforma social. Esta não poderá, em qualquer país, mas notadamente entre nós, fugir a certas características e objetivos:

1. Terá de ser uma reforma incorporada às aspirações do povo, que suba das próprias bases sociais, debatida e filtrada nas organizações de classe, e não uma reforma outorgada pela classe dominante, expressiva apenas de uma concessão sem conciliação;

2. Terá de ser uma reforma que fira de frente o problema vital da segurança econômica do indivíduo na sociedade, pois na sociedade burguesa, em cujas formas já decompostas ainda vivemos, a segurança econômica é o privilégio do proprietário, do chamado homem-independente, enquanto a forma universal de participação do indivíduo na sociedade é o trabalho, e o status que a todos corresponde é o de trabalhador;

3. Terá de produzir, a curto prazo e sem violência, com respeito dos direitos subjetivos, uma redistribuição da renda social, de modo que esta, através do salário, dos serviços coletivos e dos investimentos no setor público e privado, atinja a sociedade no seu todo, eleve o padrão 
de vida e crie o número crescente de ocupações e atividades requeridas pelo aumento e pela ativação da população.

Para que uma reforma preencha esses requisitos, não basta que ela se exprima em leis capazes de operar com resultados tecnicamente positivos sobre a realidade nacional. É necessário não esquecer que essa realidade já exprime e institucionaliza formas inveteradas de opressão social e de dominação, estabelecidas em proveito de classes, de grupos, de interesses nacionais ou estrangeiros diferenciados, e sem a liquidação progressiva e completa dessas formas de opressão não será possível criar, no país, condições que, sendo acauteladoras da justiça, também o sejam da eficiência e da continuidade do crescimento.

É à luz desses princípios e objetivos que vejo o quadro geral das grandes reformas, capazes de vitalizar a democracia brasileira. A reforma agrária nem pode ser um confisco mal disfarçado de terras, nem uma gigantesca operação imobiliária, montada à base de indenização prévia, para transformar em dinheiro líquido inversões antieconômicas, para as quais falta inclusive um mercado permanente, com capacidade de absorção. Com a reforma agrária estaremos passando do feudalismo ao capitalismo, nos campos, e dando oportunidade ao surgimento de uma nova classe agrária, dinâmica, operosa, lançada à sombra de uma assistência técnica e financeira concentrada, capaz de elevar as condições de produtividade em áreas selecionadas para o abastecimento do país.

Se não for concebida assim, num quadro circunstancial adequado, como empreendimento econômico e transformação social, a reforma corre o risco de nascer velha e desajustada de seus objetivos.

Mas nenhuma reforma - da agrária à urbana, da bancária à empresarial — poderá ser implantada hoje em nosso país se não conseguirmos, em primeiro lugar, obter de nós mesmos, da classe dirigente como das classes produtoras e trabalhadoras, um nível mínimo de confiança na viabilidade de um projeto brasileiro, com o qual possamos enfrentar o problema da desorganização crescente, que avassala nossas atividades econômicas e sociais.

O que há de excepcionalmente grave no processo contínuo dessa desorganização é que, de um lado, ele está atingindo a empresa privada, inibindo o espírito empresarial e desencorajando o investimento particular, e, de outro lado, está comprometendo a empresa pública, tornando-a economicamente inviável e gerando contradições inaceitáveis entre as suas possibilidades de sucesso e as reivindicações de seu corpo de empregados. Um país onde se desencoraja a empresa privada ao mesmo tempo que se deteriora a empresa pú- 
blica, nem se está preparando para uma expansão capitalista, nem para uma socialização, mas está simplesmente deixando-se ir ao impulso de uma corrente descendente, que pode ancorá-lo numa estagnação a longo prazo ou precipitá-lo na desordem social.

No centro desse processo instaurou-se a inflação brasileira, que de ano para ano vem atingindo taxas de crescimento mais perigosas. Sou, porém, dos que pensam com sinceridade que a inflação não pode ser julgada com critérios puramente moralísticos, como uma incontinência monetária a que não tenham sabido ou querido fugir os nossos governantes. Há critérios sociológicos a cuja luz o pendor inflacionário revela certas componentes mais irresistíveis, e sem levá-las em conta será talvez mais difícil obter a mobilização nacional que se faz necessária para conter a inflação num esforço de autodisciplina. É, assim, inegável que a pressão sobre os governos para aumentar o meio circulante tem tido origem, em grande parte, no aumento não calculado das despesas públicas e na programação de investimentos sem prévio balanço de recursos, mas também é verdade que se têm feito sentir a pressão da classe trabalhadora por uma melhoria de sua participação na renda social, através de salários mais elevados, e a pressão da classe empresarial por financiamentos para empreendimentos novos sugeridos pelas possibilidades entrevistas de ampliação do mercado interno.

O dinamismo social do país, as transformações observadas a curto prazo no comportamento da população, encorajaram e autorizaram um laissezaller inflacionário, de cujas conseqüências, a partir de certo nível, o despreparo da classe dirigente não se deu conta, e, malgrado os esforços e advertências de alguns homens responsáveis, chegamos à fase de encurtamento progressivo do período de vigência dos valores, em que a própria continuidade da produção e do desenvolvimento se vê comprometida. Daqui por diante, a persistirmos na atitude, a mantermos o processo em expansão, é a queda do investimento, a redução do número de empregos, com ilhas de prosperidade individual em torno de contratantes de obras públicas ou especuladores.

É talvez nesse momento que cabe indagar se existe, de fato, uma iniciativa milagrosa, um remédio único e genial, a que o país possa recorrer para sair do declive onde começa a não reger suas forças. Estou convencido de que não existe. O remédio não é uno, é múltiplo; a iniciativa regeneradora tem um sentido global, que ou envolve o comportamento de todo o Governo, para estender-se, em seguida, ao de todo o país, com a solidariedade ativa de todas as classes sociais, ou deixa abertas frestas, por onde se anulará o esforço e se restaurará a marcha para a desordem. 
Foi essa ação global que procurei preparar nos meses que tive a honra de ocupar o Ministério da Fazenda, e continuo a crer que a inflação brasileira nada contém que a torne inacessível a uma terapêutica coerente, aplicada sem descontinuidade e sem contradições. A política de contenção inflacionária representará sempre uma etapa preliminar indispensável, mas ficará privada de sentido se, através dela, não procurarmos a materialização de um projeto de reorganização nacional, em que se busque assegurar a viabilidade e a emancipação da economia brasileira, dentro do quadro institucional democrático e das reformas sociais a que acima me referi.

É aí que me parece oportuno completar esse quadro, e com ele, esta definição. Creio que nenhum projeto nacional é válido, nenhuma política interna auto-sustentável, se não lograr inserir o país no rumo histórico do seu tempo, e superpor harmonicamente o nacional e o universal.

Numa hora em que as grandes tensões internacionais, provocadas pela incompatibilidade ideológica e pela competição de poder, começam indubitavelmente a ceder a uma procura construtiva de condições de coexistência e de paz, a política interna do nosso país não pode, a meu ver, ser impelida por uma vaga de intransigência, que extrema posições em vez de radicalizar idéias, e conduz ao verbalismo ideológico, afastando-nos de soluções históricas capazes de representar resultados progressistas.

Já denunciei uma vez o negativismo de certas atitudes ideológicas, de sentido pseudo-revolucionário, que se colocam contra o processo dialético e retardam, em vez de acelerar, o superamento de contradições.

Os interesses reais da nação não se chocam, mas pelo contrário se harmonizam com o objetivo de segurança e elevação de nível de vida contido nas reivindicações da classe operária, mas também coincidem com os interesses da produção, ansiosa por alcançar níveis eficazes de produtividade, e libertarse de condições herdadas do passado, contrárias à consolidação do seu desenvolvimento.

Eis por que acredito que, na presente fase da evolução política brasileira, o dispositivo social capaz de manter a nação no rumo político do aprimoramento democrático e da renovação estrutural da sociedade reside numa união dos que trabalham e dos que dirigem a produção, com a participação consciente dos intelectuais, dos responsáveis pela direção da empresa pública e dos militares. Só assim levaremos a termo, nos anos decisivos que temos diante de nós, uma autêntica revolução brasileira, isto é, uma transformação de sentido emancipador, feita sob a influência de condições internas, por obra 
de contrastes que nos são próprios, e em busca de soluções orgânicas plantadas em nossa realidade.

Os extremismos de esquerda e de direita, na medida em que conseguirem comandar, mesmo temporariamente, o nosso processo político, "abrirão" inevitavelmente a revolução brasileira, tornado-a mera subsidiária de um processo internacional cujos interesses superiores nos serão impostos de fora, daí por diante.

Manter "fechado" o processo brasileiro não significa mantê-lo isolado do exterior. Significa mantê-lo, ao contrário, em contato, em correlação, em intercâmbio com o que se passa no universo, mas condicionado apenas a fatores internos e em busca de soluções de validade máxima do ponto de vista nacional.

Não creio, assim, que tenhamos uma opção ideológica, ou doutrinária, a fazer entre iniciativa estatal e iniciativa privada. O que temos é de procurar, em cada caso, em cada ocorrência, qual dessas alternativas nos permite obter níveis máximos de adequação e eficiência, para de maneira conseqüente nos fixarmos na escolha.

Também não creio numa opção necessária entre o planejamento global da economia e a ressurreição da liberdade empresarial. O planejamento "imperativo" para a empresa estatal, "indicativo" ou "limitativo" para a empresa privada - incorporou-se aos métodos da administração moderna, e é, em casos como o nosso, ainda uma decorrência da escassez de meios de que dispomos para enfrentar as tarefas do desenvolvimento, e creio mesmo que ele terá de estender-se do campo das obras públicas e dos investimentos industriais, a que se tem circunscrito, para abranger, com rigor e ao mesmo tempo flexibilidade, o domínio do comércio externo, de modo a permitir uma diferenciação crescente de mercados e um aproveitamento total das potencialidades de todas as áreas, multilaterais ou bilaterais.

Não aceito que o Brasil possa, nem deva, inscrever a sua economia no âmbito da área geopolítica a que pertencemos, e a ela subordinar o curso de seus interesses. Tive a ventura, no primeiro dos governos a que pertenci, de restaurar, em sua plenitude, as nossas relações com a área socialista, e de realizar, no segundo, um esforço leal, e a meu ver frutuoso, para normalizar nossas relações financeiras com os EUA. Pouco importa que em ambos os casos me tenham sido feitas críticas injustas e creditados aplausos indevidos. O que resulta da soma desses atos é o sentido de independência, e não de preferência ideológica, que procurei dar à política brasileira, e o princípio de fidelidade exclusiva ao interesse do nosso próprio país, o qual não está como um es- 
pectador diante do palco onde ainda se desenrola a guerra fria, mas como um participante vivo e presente da trama internacional que o rodeia.

Creio que as modificações mais recentes dessa trama, ao mesmo tempo que são auspiciosas para a paz e a coexistência, mostram que o nosso país tem estado certo em sua linha democrática, mas independente, e que devemos estender e consolidar nossa cooperação com todos os povos, sejam quais forem os regimes que pratiquem e os campos políticos a que pertençam.

A era dos grandes programas nacionais de ajuda externa, que culminou com o Plano Marshall, parece, por outro lado, claramente declinar. Não é este o lugar próprio de inventariar as causas desse declínio, para que contribuem fatores econômicos, tanto quanto mudanças de política externa e de estratégia militar, mas o certo é que os países médios e pequenos de hoje devem estar preparados para um esforço maior de autodisciplina e de integração em áreas e grupos nacionais homogêneos, ao mesmo tempo que diferenciam e sistematizam seus contatos com o exterior. A era da cooperação internacional, sob a égide das Nações Unidas, para que todos se voltam com esperança, ainda não nos fez ver seus sinais precursores.

Meus senhores, desejava agora, pedindo desculpas pela extensão deste pronunciamento, encerrá-lo com uma renovação de minha inabalável confiança no futuro do nosso país e sobretudo na vitalidade do nosso povo. Penso, de maneira especial, nas classes populares, cujo apoio solicitei e cujo convívio procurei ao ir pedir-lhes, na terra mineira que tanto amo e a que tanto devo, a outorga de confiança de um mandato legislativo.

Tomei naquele instante uma posição política e partidária, em que continuo a aprofundar minhas raízes, e que era então, como hoje, a expressão de uma convicção sincera na capacidade das nossas classes populares para impulsionarem, no sentido da renovação, da revolução democrática, o curso de nossa história.

Há países e épocas em que elites esclarecidas se avantajam, às vezes, às intuições do povo, e conseguem levá-lo a novas etapas de desenvolvimento social, que ele só mais tarde materializa. Há outros, onde o povo parece "empurrar" a sociedade, talvez sem um roteiro de marcha definido, mas com um sentido inequívoco de renovação. Creio que é este hoje o caso do Brasil, e muitas de nossas decepções e críticas são saldadas pelos testemunhos diários que, à margem de incertezas e desacertos, todos recolhemos da pujança da nação.

Que pensar, porém, de uma nação que, no limiar de uma nova era de prosperidade mundial, como esta em que o mundo está penetrando, dependesse, para o equacionamento rápido e eficaz de seus problemas e para a ado- 
ção oportuna de suas soluções, de esperar a lenta maturação das aspirações coletivas, a emergência de novas elites, sem contar com acesso pronto ao arsenal de conhecimentos incessantemente renovados e ultrapassados, que nos depara a cultura moderna?

Eis por que, se existe hoje um papel histórico reservado ao povo, na modelação de condições novas para a comunidade nacional, existe também um papel reservado às classes dirigentes, às elites, um papel a que elas podem corresponder ou não, mas cuja significação não pode ser subestimada ou incompreendida. Delas se espera um esforço consciente e supremo para se modernizarem e modernizarem o país.

Essa modernização tem suas raízes e seu processamento no campo da educação e da cultura, para que possamos evitar, ou pelo menos minimizar, os efeitos do distanciamento tecnológico que nos ameaça, a nós e a outros povos em condições evolutivas semelhantes, num momento em que a ciência faz dar um prodigioso salto para diante justamente aos países mais ricos e poderosos do globo.

Ainda agora assistimos à manifestação eloqüente do trabalhismo britânico colocando na ciência a área de desafio, em que devem ser concentrados os esforços nacionais. Não há exagero, nem inadequação, em transpor para o nosso caso essa assertiva, dizendo que o compromisso primordial da classe dirigente do nosso país deve ser a atualização da cultura brasileira, pela incorporação rápida das conquistas do pensamento moderno.

Essa modernização, ao mesmo tempo tecnológica, cultural e espiritual, não é fácil quando pensamos nos fatores materiais e culturais de que depende, mas não é impossível de ser alcançada, e sobretudo é uma opção sem alternativa. Esta revista, de espírito moderno, que em tão poucos anos conquistou tanta penetração e autoridade, dá-nos uma prova disto reunindo em torno desta mesa um grupo de homens que exprimem, nos seus respectivos campos, os mais altos padrões de capacidade e atualidade.

Gostaria de homenageá-los a todos mencionando o nome do universitário ilustre e servidor público exemplar, a quem fico devendo as palavras generosas com que me saudou na noite de hoje: Otávio Gouveia de Bulhões. É do ajustamento perfeito entre elites capazes de se modernizarem e o povo, que nos testemunha todos os dias sua vitalidade, que sinceramente espero ver surgir, por eletrólise, essa realidade que pressentimos: o futuro do Brasil. 